\title{
A Dysregulated MicroRNA-26a/EphA2 Axis Impairs Endothelial Progenitor Cell Function via the p38 MAPK/VEGF Pathway
}

\author{
Keqiang Zuo ${ }^{a}$ Kangkang Zhib Xiaoping Zhang ${ }^{\text {a }}$ Chenghui Lu ${ }^{a}$ Shi Wanga \\ Maoquan $\mathrm{Li}^{\mathrm{a}}$ Bin $\mathrm{He}^{\mathrm{c}}$ \\ aDepartment of Interventional \& Vascular Surgery, Shanghai Tenth People's Hospital, Tongji University \\ School of Medicine, bDepartment of Vascular and Endovascular Surgery, Changzheng Hospital, \\ 'Department of Anesthesiology and SICU, Xinhua Hospital, Shanghai Jiaotong University School of \\ Medicine, Shanghai, China
}

\section{Key Wods}

Endothelial progenitor cell function • MicroRNA-26a • EphA2 • p38 MAPK/VEGF pathway

\begin{abstract}
Background: Dysfunction of circulating endothelial progenitor cells (EPCS) is associated with the onset of cardiovascular disorders. Circulating microRNAs (miRNAs) have been recognized as novel biomarkers and potential therapeutic targets. Here, we examined the role of miR-26a overexpression in atherosclerosis and explored the underlying mechanisms. Methods: EPCs were obtained from patients with atherosclerosis and healthy controls. Bone marrow (BM)derived EPCs were exposed to hypoxia to mimic the atherosclerotic environment and miR-26a, EphA2 and p38 MAPK levels were measured by qRT-PCR and western blotting, and VEGF levels were determined by enzyme linked immunosorbent assay. Cell viability was assessed using the MTT assay, and luciferase activity assays confirmed EphA2 as a target of miR-26a. Results: MiR26a was overexpressed in patients with atherosclerosis and associated with EPC dysfunction. EphA2 was identified as a direct target of miR-26a. Overexpression of miR-26a downregulated EphA2 and impaired EPC function, whereas knockdown of miR-26a upregulated EphA2 and reversed hypoxia-induced EPC dysfunction. MiR-26a overexpression or knockdown modulated the activity of p38 MAPK and the levels of VEGF in EPCs. Conclusions: The role of miR-26a in atherosclerosis is mediated by its target EphA2 via a mechanism involving the p38 MAPK/ VEGF pathway.
\end{abstract}

K. Zuo and K. Zhi equally contributed to this paper.

Maoquan Li, MD,

and Bin He, M.D./Ph.D.,

\section{KARGER 125}

Department of Interventional \& Vascular Surgery, Shanghai Tenth People's Hospital, Tongji University, Yanchang Road 301, Shanghai 200072 (China) and Department of Anesthesiology and SICU, Xinhua Hospital, Shanghai Jiaotong University School of Medicine, Kongjiang Road 1665, Shanghai 200092 (China)

E-Mail Imquankxy@163.com, E-Mail doctorhebin@126.com 


\section{Introduction}

Atherosclerosis is one of the primary causes of cardiovascular disease and an important cause of mortality worldwide [1]. The formation of lipid rich plaques within the arterial wall, which is the hallmark of this disease, occurs via an inflammatory process resulting from the interaction between lipoproteins, monocyte-derived macrophages, $T$ cells and the components of the arterial wall [2]. Two processes associated with plaque, namely hypoxia and inflammation, induce the expression of vascular endothelial growth factor (VEGF) to promote angiogenesis, which is the formation of new blood vessels from pre-existing ones $[3,4]$. Endothelial progenitor cells (EPCs) are primitive bone marrow (BM) cells that possess the capacity to mature into endothelial cells (ECs) and play a role in neovascularization and vascular remodeling through the repair of endothelial lesions [5]. Because circulating EPCs can home to sites of neovascularization and differentiate into endothelial cells, they have been studied extensively for their application in cell therapy, and their transplantation has been used as a new strategy for the treatment of ischemic diseases [6]. However, the efficiency of EPC transplantation is limited by the functional integrity of EPCs, which is impaired in certain disease states. The development of strategies to improve EPC function is an area of active research.

MicroRNAs (miRNAs) are a class of small (22-nucleotide) non-coding RNAs than regulate gene expression by binding to the $3^{\prime}$ untranslated region ( $3^{\prime}$-UTR) of their target mRNAs, modulating mRNA stability and/or translation [7]. MiRNAs are differentially expressed in various cells and tissues and they regulate the expression of a wide variety of target genes [8]; therefore, they have been studied extensively as biomarkers of disease and therapeutic targets $[9,10]$. MiRNAs have been primarily investigated for their role in cancer, although their deregulation has been implicated in the pathogenesis of many human diseases. MiRNAs are highly expressed in the cardiovascular system and they have been implicated in the development of cardiovascular diseases including atherosclerosis $[11,12]$. The role of miRNAs in the regulation of angiogenesis, endothelial cell function and vascular inflammation was described previously [13]. MiR-26a, an miRNA possiblely plays a dual role in tumorigenicity, functioning either as a tumor suppressor or promoter [14]. Studies have indicated cell type-specific effects of miR-26a on neovascularization. While miR-26a promotes tumor angiogenesis in glioma [15], miR-26a expression significantly suppressed in vivo tumor-associated angiogenesis in HCC $[14,16]$. Interestingly, ectopic expression of miR-26a markedly induced endothelial cell cycle arrest and inhibited ECs migration, sprouting angiogenesis, and network tube formation in matrigel in vitro and in vivo [17]. The expression profile and functions of miR-26a in EPCs remain to be defined.

Ephrin receptor A2 (EphA2) belongs to a large family of protein tyrosine kinase receptors, the Eph family of receptors, which is divided into two subclasses depending on their ligands [18]. EphA2 has been studied extensively because of its overexpression in several human cancers including melanoma, breast cancer, prostate cancer, non-small cell lung cancer and colon cancer [19-23]. EphA2 activation plays a role in VEGF-induced endothelial cell migration [24], and EphA2 overexpression is associated with markers of angiogenesis such as high microvessel density and invasion, and increased matrix metalloprotease expression [25]. Eph receptors are involved in chronic inflammatory diseases and immune responses, and EphA2 plays a role in inflammation and cardiovascular diseases [26].

The extracellular-signal-regulated kinase (ERK)/p38 mitogen activated protein kinase (MAPK) pathway is involved in endothelial cell proliferation and migration in response to activation by several growth factors. VEGF plays an important role in vascular permeability and angiogenesis by promoting the migration, proliferation and elongation of endothelial cells [27], and VEGF is a known regulator of p38 MAPK activity in relation to several cellular functions [28].

In the present study, we investigated the role of miR-26a upregulation in EPCs and its correlation with atherosclerosis. EphA2 was identified as a direct target of miR-26a and shown to mediate the effects of miR-26a on EPC vasculogenesis, proliferation, and migration. 
Further investigation showed that the effect of the miR-26a/EphA2 axis on EPC function is mediated by a mechanism involving the p38 MAPK/VEGF pathway.

\section{Materials and Methods}

Patients and sample collection

Patients were recruited from Shanghai Tenth People's Hospital (Shanghai, China) and blood samples were collected from untreated patients. The control group consisted of healthy volunteers. All protocols were approved by the Research Ethics Committee of our institution. Informed consent was obtained from all patients before sample collection. EPCs were isolated from the blood of patients with atherosclerosis and controls using a Becton-Dickinson FACS Aria flow cytometer (BD Biosciences, San Jose, CA, USA).

\section{Cell culture and reagents}

Eight-week-old male Lewis rats were purchased from Shanghai Slac Laboratory Animal Co. Ltd. (Shanghai, China).

For hypoxic conditions, mice were fed a high-cholesterol diet (TD88051 [Harlan Teklad, Madison, WI]: $4 \mathrm{kcal} / \mathrm{g}, 15.8 \%$ fat, and $1.25 \%$ cholesterol) with an $\mathrm{F}_{102}$ of $5 \%$ delivered 60 times per hour.

For normal controls, mice were fed a regular diet ( $3.3 \mathrm{Cal} / \mathrm{g}$, 4\% fat) with intermittent air (IA) at the identical flow rate.

Mice were killed by injection of an overdose of sodium pentobarbital. The bone marrow cavities were flushed twice with $0.01 \mathrm{~mol} / \mathrm{l}$ pre-cooled phosphate-buffered saline (PBS). The cell pellets were washed twice with PBS and resuspended in M199 medium (Gibco BRL, Grand Island, NY, USA).

Bone marrow mononuclear cells (BMMCs) were obtained from the cell suspension by centrifugation through a Ficoll-isopaque density gradient. To obtain EPCs, the BMMCs were allowed to adhere to 6-well plates in M199 medium for $1 \mathrm{~h}$ at $37^{\circ} \mathrm{C}$ in a 5\% CO2 incubator. Non-adherent cells were collected and cultured in M199 medium supplemented with $10 \%$ fetal calf serum, $10 \mathrm{ng} / \mathrm{ml}$ VEGF and $2 \mathrm{ng} / \mathrm{ml}$ basic fibroblast growth factor at $37^{\circ} \mathrm{C}$ in a 5\% CO2 incubator. After $3 \mathrm{~h}$, non-adherent cells were removed and adherent cells were cultured for 7 days.

\section{Cell proliferation assay}

Cell viability was evaluated by the MTT (3-(4, 5-dimethylthiazol-2-yl)-2, 5-diphenyltetrazolium bromide) assay. Cells were seeded in triplicate in 96-well plates at a density of $1 \times 10^{4}$ cells/well and maintained in a humidified atmosphere of $5 \% \mathrm{CO} 2$ in air at $37^{\circ} \mathrm{C}$. Cells were treated with $0.125 \mathrm{mg} / \mathrm{mL}$ MTT (Invitrogen, Carlsbad, CA, USA) for $3 \mathrm{~h}$. The medium was then removed and DMSO (100 $\mu \mathrm{l} /$ well) was used to dissolve the insoluble purple formazan product. $\mathrm{OD}_{490}$ in each well was determined by a microplate reader, which reflected the number of viable cells. Assays were performed in triplicate wells. Data were presented as means and SD from three independent experiments.

\section{Luciferase reporter assay}

A fragment from the $3^{\prime}$ UTR of EphA2 containing the putative miR-26a binding site was cloned into the pGL3-Basic vector (Promega, Madison, Wisconsin, USA). The primers for the EphA2 3'-UTR were as follows: EphA2-UTR-F: CCGctcgagCCTGGAGCCCCATCGGCCAAGAATA

EphA2-UTR-R: TTCCTTTTgcggccgcAGAGCAGAAATAAGTCATTTTC

Mutant (Mut) constructs were generated by mutating the seed region of the miR-26a binding site. MiR-26a expressing or control cells were cultured in 24-well plates, and transfected with $100 \mathrm{ng}$ luciferase reporter plasmid and $5 \mathrm{ng}$. pRL-TK vector expressing Renilla luciferase (Promega) using Lipofectamine 2000 (Invitrogen). After $48 \mathrm{~h}$, cells were harvested, lysed and luciferase activity was measured using the DualLuciferase Reporter Assay System (Promega) according to the manufacturer's protocol. Renilla luciferase was used for normalization. All assays were performed in triplicate and repeated at least three times.

Real-time quantitative RT-PCR

To quantify the expression level of mature miR-26a, the isolated RNA was reverse transcribed and amplified by a two-step quantitative RT-PCR method using the Hairpin-it TM miRNA qPCR Quantitation 
Kit (Gene-pharma, Shanghai, China) according to the manufacturer's protocol. The primers used were as follows:

miR-26a-F: 5'-CTGTCAACGATACGCTAC-3'; miR-26a-R: 5' -GTAATCCAGGATAGGCTG-3'

U6-F: 5'-CTTCGGCAGCACATATAC-3'; U6-R: 5'-GAACGCTTCACGAATTTGC-3'

miR-26a for RT: 5'-GCTGTCAACGATACGCTACCTAACGGCATGACAGTGTCagccta-3'; U6 for RT: 5'-GAACGCTTCACGAATTTGC-3'

Real-time PCR for EphA2 was performed using the ABI 7300System (Bio-Rad, CA) with the QuantiTect SYBR Green PCR mixture (Invitrogen). The primers used were as follows: EphA2-F: 5'-CACTTACCGCAAGAAGGGAGA-3'; EphA2-R: 5'-ACAGCCACGCCGCCAATCA-3'.

\section{miRNA transfection}

MiR-26a was overexpressed or silenced in EPCs using recombinant lentivirus vectors containing premiR-26a, negative control precursor miRNA, anti-miRNA against miR-26a or negative control for the antimiRNA. The vectors together with packaging vectors were transfected into EPCs using Lipofectamine 2000 (Invitrogen, Carlsbad, CA) and the transfection results were verified by qRT-PCR.

Enzyme linked immunosorbent assay (ELISA)

The levels of VEGF were determined by ELISA using a commercially available kit (R\&D Systems, Minneapolis MN; BD Biosciences, San Diego, CA) according to the manufacturer's instructions. All assays were performed in duplicate.

\section{Western blot analysis}

For western blot analysis, EPCs were lysed in lysis buffer containing $20 \mathrm{mM}$ Tris (pH 7.5), $150 \mathrm{mM} \mathrm{NaCl}$, $1 \mathrm{mM}$ EDTA, $1 \mathrm{mM}$ EGTA, $1 \%$ Triton X-100, $2.5 \mathrm{mM}$ sodium pyrophosphate, $1 \mathrm{mM} \beta$-glycerophosphate, $1 \mathrm{mM}$ $\mathrm{Na} 3 \mathrm{VO} 4,1 \mu \mathrm{g} / \mathrm{ml}$ leupeptin, and $1 \mathrm{mM}$ PMSF and centrifuged at 12,000 rpm for $5 \mathrm{~min}$. Aliquots containing 20 $\mu \mathrm{g}$ of protein were separated by sodium dodecyl sulfate polyacrylamide gel electrophoresis and transferred onto polyvinylidene difluoride membranes (Milipore). After blocking in 5\% nonfat milk in PBS, blots were incubated with primary antibodies overnight at $4^{\circ} \mathrm{C}$ followed by incubation with horseradish peroxydase conjugated secondary goat anti-rabbit antibodies (1:4000 dilution, PerkinElmer, USA). Primary antibodies used and their dilutions were as follows: anti-EphA2 (1:500, Santa Cruz Biotechnology, Santa Cruz, CA), anti-phospho-p38 MAPK and anti p38 MAPK (1:500, Cell Signaling Technology, Beverly, MA). GAPDH was detected as the loading control.

\section{EPC tube formation and Transwell cell migration assays}

In vitro tube formation was assessed as described previously [29]. Briefly, basement membrane extracts were plated in 96 -well plates at $37^{\circ} \mathrm{C}$ to form a reconstituted basement membrane. EPCs were collected by trypsin/EDTA and $1 \times 10^{4}$ cells in $100 \mathrm{ml}$ medium were seeded on Matrigel and incubated at $37^{\circ} \mathrm{C}$ for $6 \mathrm{~h}$. Tube formation was examined under an inverted light microscope and measured by analyzing five representative fields and calculating the total tube length in each group. All data are the results of three independent experiments performed in triplicate. The results were expressed as relative to the control group.

For Transwell cell migration assays, $600 \mu \mathrm{l}$ medium containing 10\% fetal bovine serum (FBS) was added to the lower chamber of Costar Transwell Polycarbonate Permeable Supports (Corning, NY, USA). EPCs $\left(5 \times 10^{4}\right)$ in $100 \mu \mathrm{l}$ medium were added to the upper chamber and incubated at $37^{\circ} \mathrm{C}$ for $3 \mathrm{~h}$, after which the cell suspensions were removed from the upper chamber and membranes were fixed in $4 \%$ paraformaldehyde. Migrated cells were stained with Hoechst 33342 reagent for $30 \mathrm{~min}$ and counted in five representative fields under a fluorescent microscope.

\section{Statistical analysis}

Results are presented as means \pm standard errors of the mean of three independent experiments. Comparisons were performed using the Student's t test. Data were analyzed using SPSS software version 14 (SPSS, Chicago, IL, USA). A p value $<0.05$ was considered statistically significant. 
A

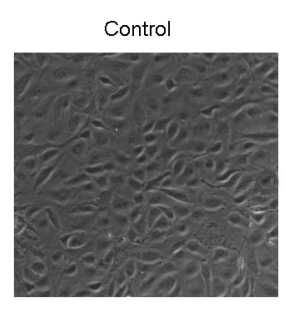

B

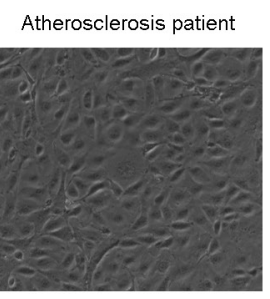

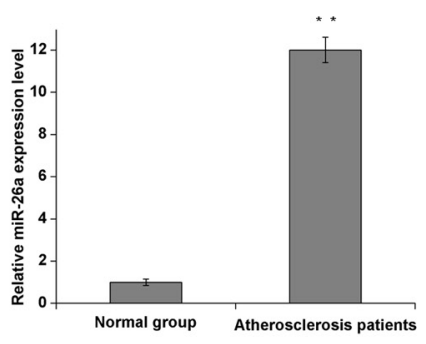

C

$\mathrm{CD} 45$
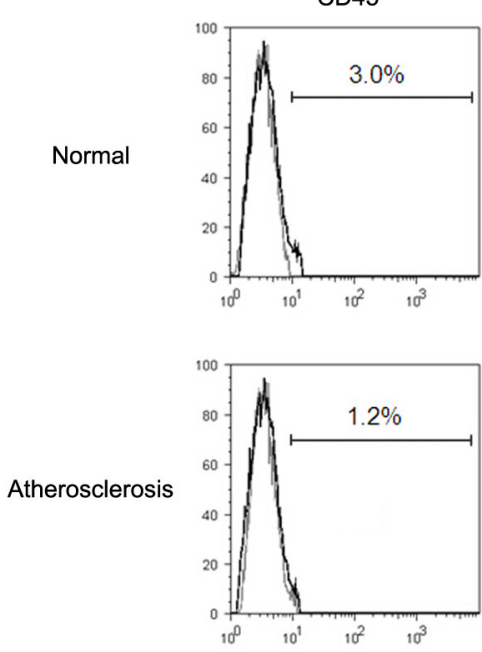
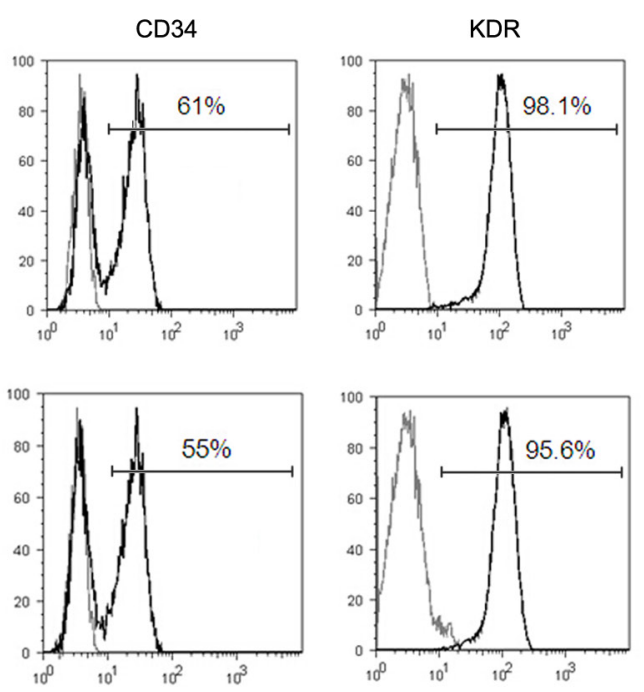

Fig. 1. Identification of EPCs and quantification of miR-26a expression levels in atherosclerosis patients and health controls. (A) Morphology of healthy and diseased EPCs. (B) RT-qPCR quantification of miR-26a from total RNA extracted from healthy and diseased EPCs $\left({ }^{*} p<0.01\right.$ by Student's $t$ test). (C) Expression of EPC surface antigens by flow cytometric analysis.

\section{Results}

MiR-26a is upregulated in endothelial progenitor cells and associated with atherosclerosis

EPCs were separated from the blood of patients with atherosclerosis and healthy controls and analyzed by phase contrast microscopy, which showed a monolayer of cobblestoneappearing cells typical of late EPCs (Fig. 1A). Quantification of miR-26a expression by RTqPCR showed significantly higher levels in EPCs of atherosclerosis patients than in those of the control group ( $p<0.01$ ) (Fig. 1B). Both EPCs were negative for the hematopoietic marker CD45 yet the CD34 precursor gene. They also expressed endothelial markers KDR (Fig. 1C).

Hypoxia upregulates miR-26a in EPCs in correlation with decreased cell viability, tube formation ability and migration

The expression of miR-26a was examined in EPCs under conditions of hypoxia to mimic the atherosclerotic environment. The results of qRT-PCR showed significantly increased levels of miR-26a in EPCs exposed to hypoxia than in control EPCs ( $<<0.05$ ) (Fig. 2A). Assessment of cell viability using the WST-1 assay showed a significant reduction in the proliferation of EPCs up to day 9 under conditions of hypoxia compared to the untreated controls ( $p<0.05)$ (Fig. 2B). To examine the effect of hypoxia on the angiogenic capacity of EPCs, tube formation and EPC migration were assessed under conditions of hypoxia. The results showed that hypoxia inhibited tube formation by approximately $65 \%$ and migration by approximately $45 \%$ in EPCs (p < 0.05) (Fig. 2C). 


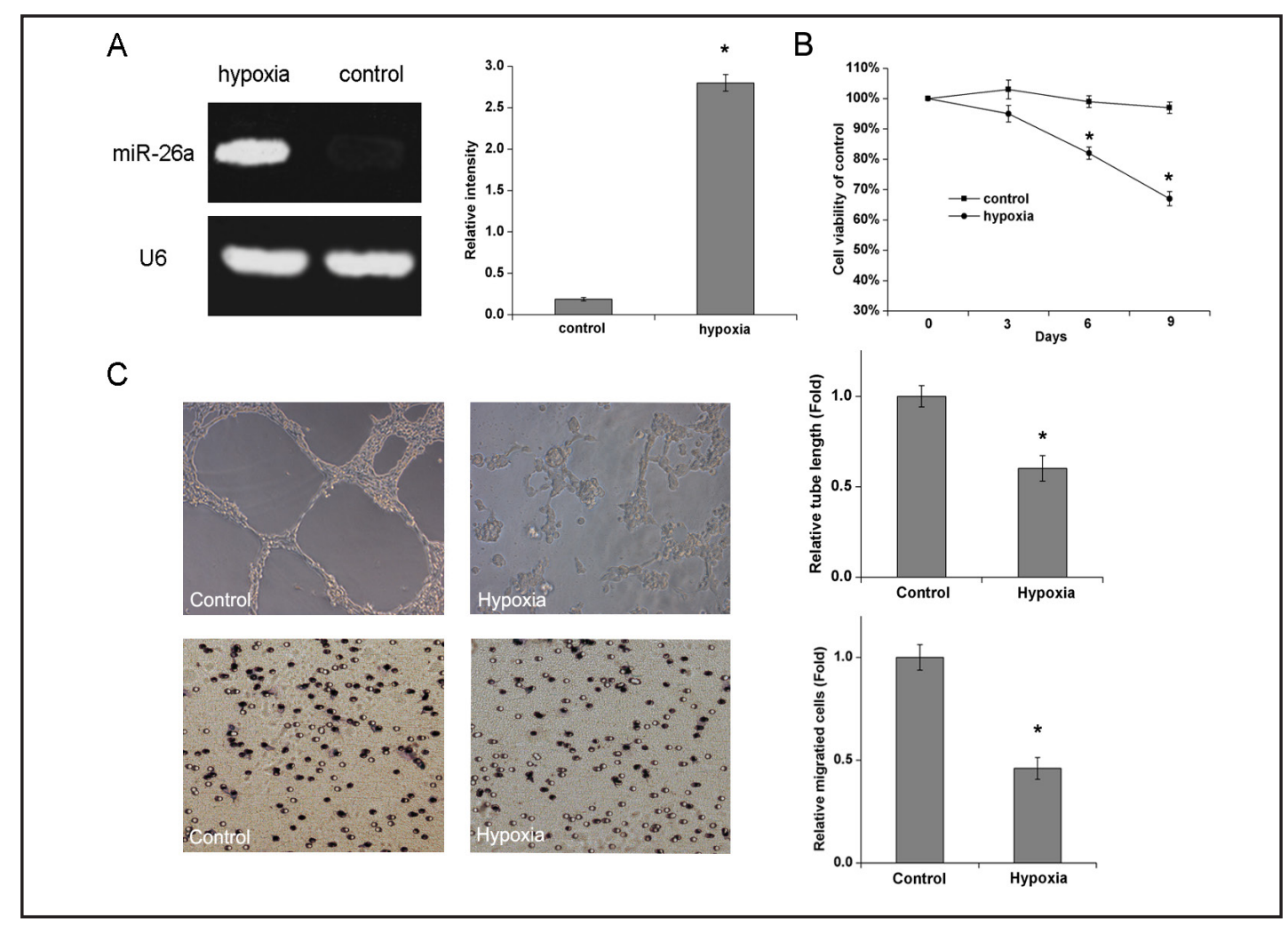

Fig. 2. MiR-26a levels and angiogenic activity in EPCs under hypoxic and normal conditions. (A) RT-qPCR of miR-26a from total RNA extracts from EPCs under hypoxic and normal conditions $\left({ }^{*} p<0.05\right)$. (B) Assessment of cell proliferation by the MTT assay in EPCs grown under normal and hypoxic conditions $\left({ }^{*} \mathrm{p}<0.05\right)$. (C) Angiogenic abilities of EPCs under hypoxic and normal conditions as determined by tube formation and migration assays. Tube length was measured and migrated cells were stained (representative pictures are shown) and counted (right panels, $n=3$ ).

\section{Mir-26a downregulates EphA2 and impairs EPC function}

Target genes of miR-26a were identified using the online miRNA target prediction programs miRanda (http://www.microrna.org), TargetScan (http://www. targetscan.org) and PicTar (http://www.pictar.bio.nyu.edu). Approximately 100 targets of miR-26a were predicted from these programs. EphA2 was of particular interest and was thus explored as a potential target mediating the effect of miR-26a in EPCs.

Overexpression of miR-26a was confirmed by qRT-PCR and its effect on the expression of EphA2 was measured by RT-PCR and western blotting. The results showed that ectopic expression of miR-26a significantly downregulated the expression of EphA2 in EPCs at the mRNA (more than 5-fold downregulation) and protein levels (Fig. 3A). Overexpression of miR-26a significantly inhibited cell proliferation, tube formation and the migration ability of EPCs ( $<<0.05$ all) (Fig. 3B and C).

Mir-26a knockdown upregulates EphA2 and reverses hypoxia-induced EPC dysfunction

Knockdown of miR-26a by anti-miR transfection significantly upregulated the expression of EphA2 at the mRNA (approximately 3.2-fold upregulation) and protein levels in EPCs, as determined by qRT-PCR and western blotting (Fig. 4A). Furthermore, knockdown of miR-26a and the consequent upregulation of EphA2 reversed the effect of hypoxia on impairing EPC function, as determined by the restoration of tube formation and migration abilities (Fig. 4B). 
A

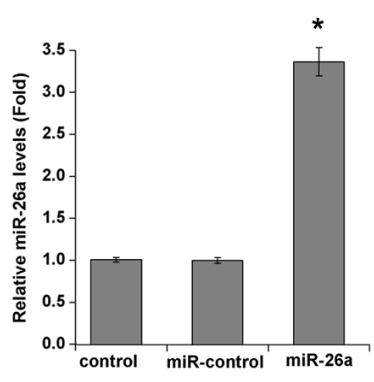

B

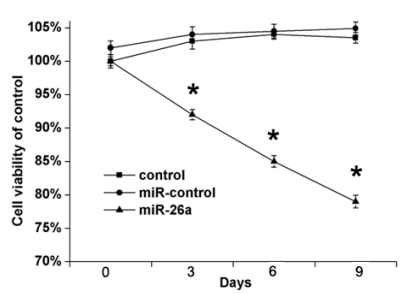

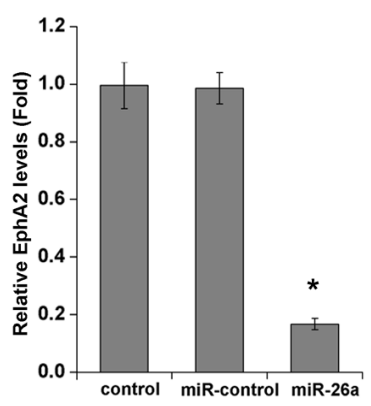

C

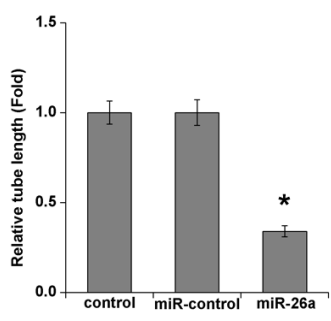

miR-control miR-26a

EphA2

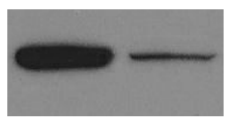

GAPDH
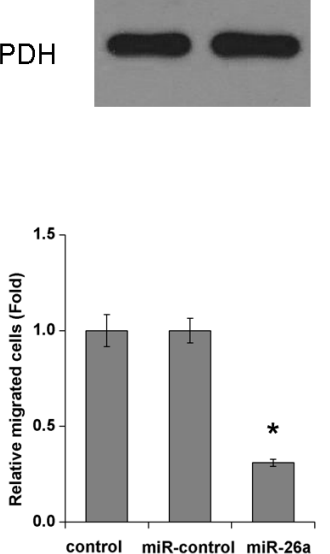

Fig. 3. Overexpression of miR-26a under normal conditions downregulated EphA2 expression and impaired EPC function. (A) Overexpression of miR-26a downregulated EphA2 expression $\left({ }^{*} p<0.05\right)$, inhibited cell proliferation (B), and microtubule formation and EPC migration (C) $\left({ }^{*} \mathrm{p}<0.05\right)$.

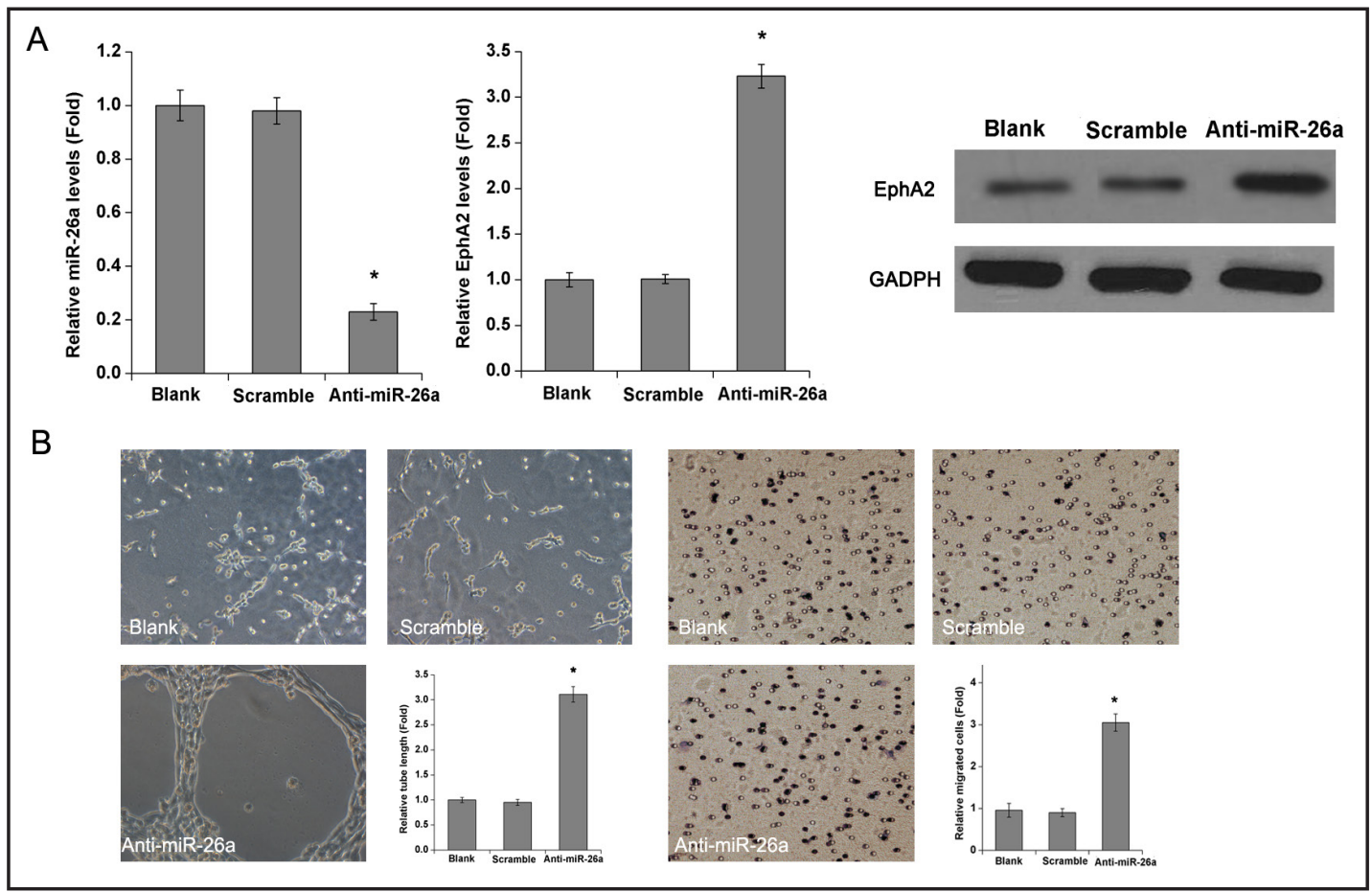

Fig. 4. Knockdown of miR-26a under hypoxic conditions restored EphA2 expression and EPC function. (A) RT-PCR results show that miR-26a oligonucleotide antagomir transfection upregulated EphA2 expression. (B) Knockdown of miR-26a restored hypoxia-impaired EPC vasculogenesis and migration $\left({ }^{*} \mathrm{p}<0.05\right)$.

EphA2 is a direct target of miR-26a

Figure 5A shows the sequence alignment of the miR26a seed region and the predicted miR-26a binding site in the 3 '-UTR of wild-type (WT) EphA2, as well as a mutant (MUT) 


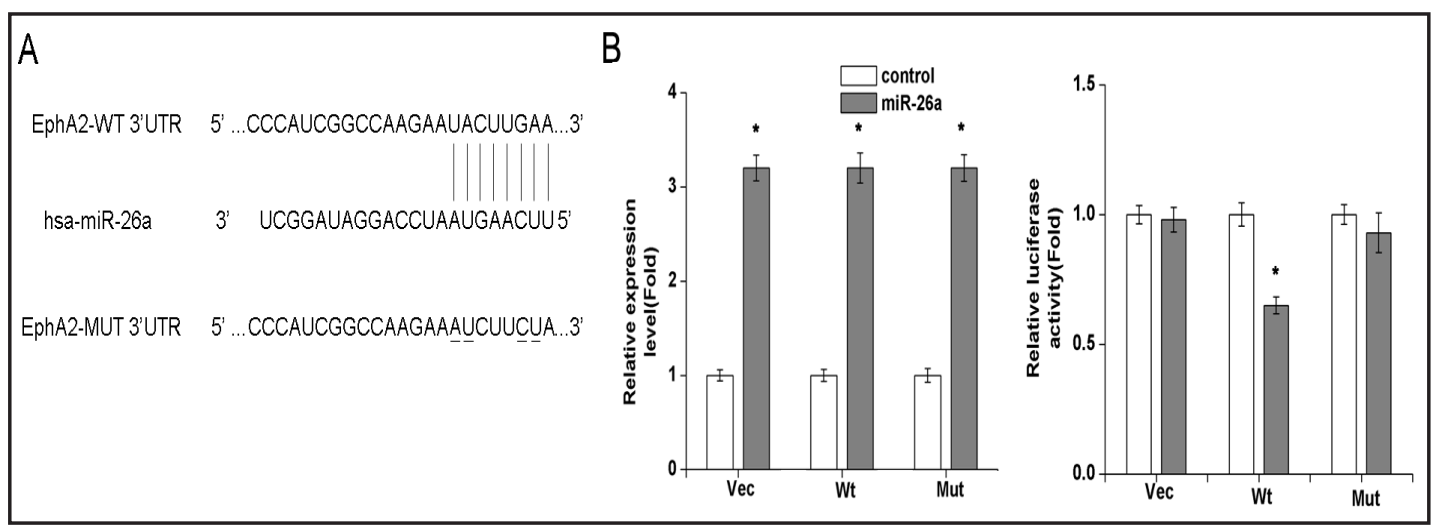

Fig. 5. miR-26a binds directly to the EphA2 3'UTR region. (A) Construct sequence alignment of the miR-26a seed region and the predicted binding site in the EphA2 3'-UTR (WT), and the construct obtained by site-directed mutagenesis of four base pairs of the miR-26a seed-sequence (Mut). (B) Constructs containing the WT or Mut 3'-UTR of EphA2 were transfected into EPCs and the relative luciferase activity was measured $\left({ }^{*} \mathrm{p}<0.05\right)$.

Fig. 6. miR-26a/EphA2 regulate the expression of VEGF and phosphorylation of p38 MAPK in EPCs under normal and hypoxic conditions.(A) Stable overexpression of miR-26a under normal conditions decreased the protein levels of phosphorylated (p) p38MAPK. Total p38MAPK was unaffected. (B) VEGF levels were measured by ELISA $(* p<0.05)$. (C) Knockdown of miR-26a under hypoxic conditions increased the levels of phosphorylated (p) p38MAPK. Total p38MAPK was unaffected. (D) VEGF levels were measured by ELISA $\left({ }^{*} \mathrm{p}<0.05\right)$.

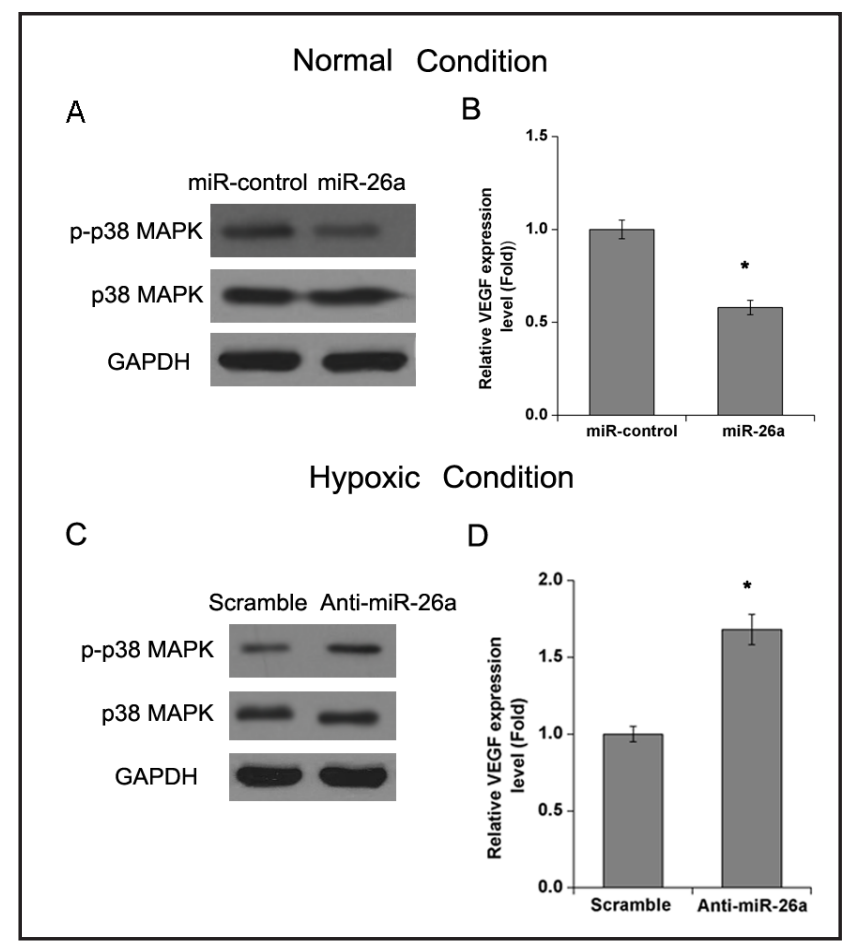

3'-UTR or EphA2 generated by site-directed mutagenesis. The WT or MUT 3'-UTR of EphA2 containing the putative miR-26a binding site was cloned downstream of the luciferase reporter gene. Luciferase reporter assays showed that miR-26a significantly decreased the luciferase activity of the EphA2 WT 3' UTR but not that of the mutant, indicating that EphA2 is a direct target of miR-26a (Fig. 5B).

The effect of miR-26a/EphA2 on EPC function is mediated by the p38 MAPK/VEGF pathway

To explore the mechanism by which miR-26a modulates EPC function, the expression of VEGF and the activation status of p38MAPK were examined in EPCs after overexpression or antagomir mediated knockdown of miR26a. The results showed that miR-26a overexpression significantly reduced the levels of phospho-p38 MAPK and downregulated VEGF expression (Fig. 6A and B), whereas anti-miR-26a had the opposite effect (Fig. 6C and D) (p $<0.05$ all). 


\section{Discussion}

In the present study, we investigated the effect of miR-26a overexpression on EPC function and explored the underlying mechanisms. Hypoxia-induced EPC dysfunction, as determined by decreased viability and impaired tube formation and migration ability, was accompanied by miR-26a upregulation. Furthermore, ectopic expression of miR-26a mimicked the effects of hypoxia on EPC function. We identified the EphA2 receptor as a direct target of miR-26a and showed that the effect of miR-26a on the impairment of EPC function is mediated by its target EphA2 via a mechanism involving the p38 MAPK/VEGF pathway.

MiRNA dysregulation plays important roles in different phases of atherosclerosis development, from plaque formation to endothelial cell function and angiogenesis [30]. Several miRNAs have been identified that are up- or down-regulated in endothelial dysfunction leading to the development of atherosclerosis. Among them, miR-126 is one of the most abundant miRNAs in ECs and plays an important role in angiogenesis and vascular integrity [31], in addition to having a protective effect against atherosclerosis in mice by targeting RGS16 [32]. MiR-181b and miR10a are involved in atherosclerosis development by modulating the activity of the NF- $\mathrm{BB}$ pathway [33,34]. Several miRNAs have been implicated in the regulation of angiogenesis: miR-126, miR-130a, miR-210 and the miR23miR27-miR24 cluster promote angiogenic activity, whereas miR-221/miR222, miR-92a and miR217 inhibit angiogenesis in endothelial cells [35-41]. Overexpression of miR-34 impairs EPC angiogenesis in parallel with the downregulation of SIRT1 [42]. In the present study, we showed that miR-26a is upregulated and plays a role in EPC dysfunction in atherosclerosis.

MiR26a has been shown to function in both promoting and inhibiting cell proliferation in different cell types. MiR-26a inhibits osteogenic differentiation of adipose tissue-derived stem cells [43] and promotes tumor formation in glioma [44]. MiR-26a promotes vascular smooth muscle cell proliferation by targeting TGF- $\beta$ /BMP pathway signaling [45]. On the other hand, ectopic expression of miR-26a induced cell cycle arrest in endothelial cells and inhibited EC migration, angiogenesis and tube formation [17]. In hepatocellular carcinoma (HCC), miR-26a was shown to promote cell cycle arrest in vitro and adeno-associated virusmediated miR-26a delivery suppressed cell proliferation and promoted apoptosis in vivo [46]. Consistently, miR-26a attenuated cell proliferation and impaired cell cycle progression by targeting the Polycomb complex protein EZH2 in association with lymphomagenesis [47]. MiR-26a was shown to play a role in angiogenesis in HCC through its effect on the PI3K-C2 $\alpha$ / Akt/VEGF signaling pathway [16]. Ectopic expression of miR-26a downregulated VEGFA and impaired migration and tube formation in human umbilical vein endothelial cells. These findings are consistent with the results of the present study showing that ectopic expression of miR-26a inhibited VEGF expression and suppressed the angiogenic potential of EPCs, whereas anti-miR-26a restored VEGF levels and angiogenic activity.

We identified EphA2 as a direct target of miR-26a and elucidated a potential mechanism by which miR-26a affects EPC function by modulating VEGF expression and the activity of the p38 MAPK pathway through its target EphA2. Ephs and ephrins were originally identified in a tumorigenesis model, and research on Eph-ephrin interactions have been predominantly focused on their role in carcinogenesis. However, later studies showed their involvement in a variety of chronic diseases [26]. EphA2 expression in endothelial cells has been implicated in inflammatory processes associated with atherosclerosis, such as proinflammatory gene expression [48] and endothelial barrier dysfunction $[49,50]$, as well as in angiogenesis [51, 52]. Enhanced expression of EphA2 and its ligand ephrinA1 in activated endothelial cells suggests that they play a role as mediators of atherogenic inflammation [26]. Furthermore, increased endothelial EphA2 signaling during endothelial cell activation promotes the expression of proinflammatory genes, thus inducing an inflammatory response. The role of EphA2 in angiogenesis has been well characterized, in particular in models of tumorigenesis, ischemia-reperfusion injury and hypoxia [52-56]. These data support the findings of the present study by illustrating the role of EphA2 in inflammation and vascular remodeling and the correlation between EphA2 signaling and atherosclerosis. 
In the present study, we showed that miR-26a overexpression inhibited the activation of p38 MAPK and downregulated VEGF expression, whereas silencing of miR-26a had the opposite effects. VEGF is one of the most potent angiogenic factors and it increases vascular permeability and endothelial cell survival in vessels $[57,58]$, and activation of p38 MAPK plays a role in the modulation of VEGF levels. These findings together with the results of the present study confirming the effect of miR-26a on the downregulation of VEGF suggest a potential mechanism underlying EPC dysfunction involving miR-26a and the p38 MAPK/ VEGF pathway. Further studies aimed at elucidating the precise mechanism by which miR26a and its target EphA2 modulate EPC function are warranted.

In conclusion, in the present study we showed that miR-26a is upregulated in EPCs in atherosclerosis and its ectopic expression induces EPC dysfunction, mimicking the effects of hypoxia. We identified EphA2 as a direct target of miR-26a and showed that miR-26a overexpression or silencing modulated EphA2 levels concomitant with alterations in the angiogenic and proliferative abilities of EPCs, suggesting that the effects of miR-26a on the function of EPCs are mediated by EphA2. Furthermore, miR-26a overexpression or silencing modulated the activity of p38 MAPK and the levels of VEGF. Taken together, our findings suggest that the role of miR-26a in atherosclerosis is mediated by a mechanism that involves its target EphA2 and the p38 MAPK pathway, providing potential new biomarkers and therapeutic targets for patients with atherosclerosis.

\section{Disclosure Statement}

We declare that we have no conflicts of interest.

\section{Acknowledgments}

The study was supported by the National Natural Science Foundation of China (81270003, 81470390) and the Program of Science and Tenchnology Commission of Shanghai Municipality 13ZR1414500 and 11ZR1433200.

\section{References}

1 Hansson GK, Libby P: The immune response in atherosclerosis: A double-edged sword. Nat Rev Immunol 2006;6:508-519.

-2 Glass CK, Witztum JL: Atherosclerosis. The road ahead. Cell 2001;104:503-516.

- Huang S, Tang Y, Cai X, Peng X, Liu X, Zhang L, Xiang Y, Wang D, Wang X, Pan T: Celastrol inhibits vasculogenesis by suppressing the vegf-induced functional activity of bone marrow-derived endothelial progenitor cells. Biochem Biophys Res Commun;423:467-472.

4 Sluimer JC, Daemen MJ: Novel concepts in atherogenesis: Angiogenesis and hypoxia in atherosclerosis. J Pathol 2009;218:7-29.

5 Szmitko PE, Fedak PW, Weisel RD, Stewart DJ, Kutryk MJ, Verma S: Endothelial progenitor cells: New hope for a broken heart. Circulation 2003;107:3093-3100.

6 Kalka C, Masuda H, Takahashi T, Kalka-Moll WM, Silver M, Kearney M, Li T, Isner JM, Asahara T: Transplantation of ex vivo expanded endothelial progenitor cells for therapeutic neovascularization. Proc Natl Acad Sci U S A 2000;97:3422-3427.

7 Shukla GC, Singh J, Barik S: Micrornas: Processing, maturation, target recognition and regulatory functions. Mol Cell Pharmacol;3:83-92.

8 Pasquinelli AE: Micrornas and their targets: Recognition, regulation and an emerging reciprocal relationship. Nat Rev Genet;13:271-282.

-9 Kloosterman WP, Plasterk RH: The diverse functions of micrornas in animal development and disease. Dev Cell 2006;11:441-450.

10 Chen X, Ba Y, Ma L, Cai X, Yin Y, Wang K, Guo J, Zhang Y, Chen J, Guo X, Li Q, Li X, Wang W, Wang J, Jiang X, Xiang Y, Xu C, Zheng P, Zhang J, Li R, Zhang H, Shang X, Gong T, Ning G, Zen K, Zhang CY: Characterization of micrornas in serum: A novel class of biomarkers for diagnosis of cancer and other diseases. Cell Res 2008;18:997-1006. 


\begin{tabular}{|c|c|c|}
\hline Cellular Physiology & Cell Physiol Biochem 2015;35:477-488 & \\
\hline and Biochemistry & $\begin{array}{l}\text { DOI: } 10.1159 / 000369713 \\
\text { Published online: January } 16,2015\end{array}$ & $\begin{array}{l}\text { O } 2015 \text { S. Karger AG, Basel } \\
\text { www.karger.com/cpb }\end{array}$ \\
\hline
\end{tabular}

11 Zhang C: Micrornas: Role in cardiovascular biology and disease. Clin Sci (Lond) 2008;114:699-706.

12 Latronico MV, Catalucci D, Condorelli G: Emerging role of micrornas in cardiovascular biology. Circ Res 2007;101:1225-1236.

13 Urbich C, Kuehbacher A, Dimmeler S: Role of micrornas in vascular diseases, inflammation, and angiogenesis. Cardiovasc Res 2008;79:581-588.

14 Yang X, Zhang XF, Lu X, Jia HL, Liang L, Dong QZ, Ye QH, Qin LX: Microrna-26a suppresses angiogenesis in human hepatocellular carcinoma by targeting hepatocyte growth factor-cmet pathway. Hepatology;59:1874-1885.

15 Qian X, Zhao P, Li W, Shi ZM, Wang L, Xu Q, Wang M, Liu N, Liu LZ, Jiang BH: Microrna-26a promotes tumor growth and angiogenesis in glioma by directly targeting prohibitin. CNS Neurosci Ther;19:804-812.

-16 Chai ZT, Kong J, Zhu XD, Zhang YY, Lu L, Zhou JM, Wang LR, Zhang KZ, Zhang QB, Ao JY, Wang M, Wu WZ, Wang L, Tang ZY, Sun HC: Microrna-26a inhibits angiogenesis by down-regulating vegfa through the pik3c2alpha/akt/hif-1alpha pathway in hepatocellular carcinoma. PLoS One;8:e77957.

17 Icli B, Wara AK, Moslehi J, Sun X, Plovie E, Cahill M, Marchini JF, Schissler A, Padera RF, Shi J, Cheng HW, Raghuram S, Arany Z, Liao R, Croce K, MacRae C, Feinberg MW: Microrna-26a regulates pathological and physiological angiogenesis by targeting bmp/smad1 signaling. Circ Res;113:1231-1241.

18 Pasquale EB: The eph family of receptors. Curr Opin Cell Biol 1997;9:608-615.

19 Easty DJ, Bennett DC: Protein tyrosine kinases in malignant melanoma. Melanoma Res 2000;10:401-411.

-20 Zelinski DP, Zantek ND, Stewart JC, Irizarry AR, Kinch MS: Epha2 overexpression causes tumorigenesis of mammary epithelial cells. Cancer Res 2001;61:2301-2306.

21 Walker-Daniels J, Coffman K, Azimi M, Rhim JS, Bostwick DG, Snyder P, Kerns BJ, Waters DJ, Kinch MS: Overexpression of the epha2 tyrosine kinase in prostate cancer. Prostate 1999;41:275-280.

22 D'Amico TA, Aloia TA, Moore MB, Conlon DH, Herndon JE, 2nd, Kinch MS, Harpole DH, Jr: Predicting the sites of metastases from lung cancer using molecular biologic markers. Ann Thorac Surg 2001;72:11441148.

23 Ogawa K, Pasqualini R, Lindberg RA, Kain R, Freeman AL, Pasquale EB: The ephrin-a1 ligand and its receptor, epha2, are expressed during tumor neovascularization. Oncogene 2000;19:6043-6052.

24 Cheng N, Brantley DM, Liu H, Lin Q, Enriquez M, Gale N, Yancopoulos G, Cerretti DP, Daniel TO, Chen J: Blockade of epha receptor tyrosine kinase activation inhibits vascular endothelial cell growth factorinduced angiogenesis. Mol Cancer Res 2002;1:2-11.

25 Lin YG, Han LY, Kamat AA, Merritt WM, Landen CN, Deavers MT, Fletcher MS, Urbauer DL, Kinch MS, Sood AK: Epha2 overexpression is associated with angiogenesis in ovarian cancer. Cancer 2007;109:332-340.

-26 Funk SD, Orr AW: Ephs and ephrins resurface in inflammation, immunity, and atherosclerosis. Pharmacol Res;67:42-52.

27 Carmeliet P: Mechanisms of angiogenesis and arteriogenesis. Nat Med 2000;6:389-395.

28 Hoeben A, Landuyt B, Highley MS, Wildiers H, Van Oosterom AT, De Bruijn EA: Vascular endothelial growth factor and angiogenesis. Pharmacol Rev 2004;56:549-580.

29 Wang HW, Lo HH, Chiu YL, Chang SJ, Huang PH, Liao KH, Tasi CF, Wu CH, Tsai TN, Cheng CC, Cheng SM: Dysregulated mir-361-5p/vegf axis in the plasma and endothelial progenitor cells of patients with coronary artery disease. PLoS One;9:e98070.

30 Menghini R, Stohr R, Federici M: Micrornas in vascular aging and atherosclerosis. Ageing Res Rev;17:68-78.

31 Wei Y, Nazari-Jahantigh M, Neth P, Weber C, Schober A: Microrna-126, -145, and -155: A therapeutic triad in atherosclerosis? Arterioscler Thromb Vasc Biol;33:449-454.

-32 Zernecke A, Bidzhekov K, Noels H, Shagdarsuren E, Gan L, Denecke B, Hristov M, Koppel T, Jahantigh MN, Lutgens E, Wang S, Olson EN, Schober A, Weber C: Delivery of microrna-126 by apoptotic bodies induces cxcl12-dependent vascular protection. Sci Signal 2009;2:ra81.

-33 Sun X, Icli B, Wara AK, Belkin N, He S, Kobzik L, Hunninghake GM, Vera MP, Blackwell TS, Baron RM, Feinberg MW: Microrna-181b regulates nf-kappab-mediated vascular inflammation. J Clin Invest;122:1973-1990.

-34 Fang Y, Shi C, Manduchi E, Civelek M, Davies PF: Microrna-10a regulation of proinflammatory phenotype in athero-susceptible endothelium in vivo and in vitro. Proc Natl Acad Sci U S A;107:13450-13455.

35 Wang S, Aurora AB, Johnson BA, Qi X, McAnally J, Hill JA, Richardson JA, Bassel-Duby R, Olson EN: The endothelial-specific microrna mir-126 governs vascular integrity and angiogenesis. Dev Cell 2008;15:261271.

36 Bonauer A, Carmona G, Iwasaki M, Mione M, Koyanagi M, Fischer A, Burchfield J, Fox H, Doebele C, Ohtani K, Chavakis E, Potente M, Tjwa M, Urbich C, Zeiher AM, Dimmeler S: Microrna-92a controls angiogenesis 


\section{Cellular Physiology $\quad$ Cell Physiol Biochem 2015;35:477-488 and Biochemistry \begin{tabular}{l|l} 
DOI: 10.1159/000369713 & C 2015 S. Karger AG, Base \\
Published onme: January 16, 2015 & wwwarger.com/cpb
\end{tabular} \\ Zuo et al.: MicroRNA-26a Induces EPC Dysfunction}

and functional recovery of ischemic tissues in mice. Science 2009;324:1710-1713.

-37 Fasanaro P, D'Alessandra Y, Di Stefano V, Melchionna R, Romani S, Pompilio G, Capogrossi MC, Martelli F: Microrna-210 modulates endothelial cell response to hypoxia and inhibits the receptor tyrosine kinase ligand ephrin-a3. J Biol Chem 2008;283:15878-15883.

-38 Chen Y, Gorski DH: Regulation of angiogenesis through a microrna (mir-130a) that down-regulates antiangiogenic homeobox genes gax and hoxa5. Blood 2008;111:1217-1226.

-39 Zhou Q Gallagher R, Ufret-Vincenty R, Li X, Olson EN, Wang S: Regulation of angiogenesis and choroidal neovascularization by members of microrna-23 27 24 clusters. Proc Natl Acad Sci U S A;108:8287-8292.

40 Suarez Y, Fernandez-Hernando C, Pober JS, Sessa WC: Dicer dependent micrornas regulate gene expression and functions in human endothelial cells. Circ Res 2007;100:1164-1173.

41 Menghini R, Casagrande V, Cardellini M, Martelli E, Terrinoni A, Amati F, Vasa-Nicotera M, Ippoliti A, Novelli G, Melino G, Lauro R, Federici M: Microrna 217 modulates endothelial cell senescence via silent information regulator 1. Circulation 2009;120:1524-1532.

42 Zhao T, Li J, Chen AF: Microrna-34a induces endothelial progenitor cell senescence and impedes its angiogenesis via suppressing silent information regulator 1. Am J Physiol Endocrinol Metab;299:E110-116.

43 Luzi E, Marini F, Sala SC, Tognarini I, Galli G, Brandi ML: Osteogenic differentiation of human adipose tissuederived stem cells is modulated by the mir-26a targeting of the smad1 transcription factor. J Bone Miner Res 2008;23:287-295.

-44 Huse JT, Brennan C, Hambardzumyan D, Wee B, Pena J, Rouhanifard SH, Sohn-Lee C, le Sage C, Agami R, Tuschl T, Holland EC: The pten-regulating microrna mir-26a is amplified in high-grade glioma and facilitates gliomagenesis in vivo. Genes Dev 2009;23:1327-1337.

45 Leeper NJ, Raiesdana A, Kojima Y, Chun HJ, Azuma J, Maegdefessel L, Kundu RK, Quertermous T, Tsao PS, Spin JM: Microrna-26a is a novel regulator of vascular smooth muscle cell function. J Cell Physiol;226:1035-1043.

-46 Kota J, Chivukula RR, O'Donnell KA, Wentzel EA, Montgomery CL, Hwang HW, Chang TC, Vivekanandan P, Torbenson M, Clark KR, Mendell JR, Mendell JT: Therapeutic microrna delivery suppresses tumorigenesis in a murine liver cancer model. Cell 2009;137:1005-1017.

47 Sander S, Bullinger L, Wirth T: Repressing the repressor: A new mode of myc action in lymphomagenesis. Cell Cycle 2009;8:556-559.

48 Foubert P, Silvestre JS, Souttou B, Barateau V, Martin C, Ebrahimian TG, Lere-Dean C, Contreres JO, Sulpice E, Levy BI, Plouet J, Tobelem G, Le Ricousse-Roussanne S: Psgl-1-mediated activation of ephb4 increases the proangiogenic potential of endothelial progenitor cells. J Clin Invest 2007;117:1527-1537.

-49 Hahn C, Schwartz MA: Mechanotransduction in vascular physiology and atherogenesis. Nat Rev Mol Cell Biol 2009;10:53-62.

50 Libby P, Ridker PM, Maseri A: Inflammation and atherosclerosis. Circulation 2002;105:1135-1143.

51 Dottori M, Hartley L, Galea M, Paxinos G, Polizzotto M, Kilpatrick T, Bartlett PF, Murphy M, Kontgen F, Boyd AW: Epha4 (sek1) receptor tyrosine kinase is required for the development of the corticospinal tract. Proc Natl Acad Sci U S A 1998;95:13248-13253.

52 Brantley-Sieders DM, Fang WB, Hwang Y, Hicks D, Chen J: Ephrin-a1 facilitates mammary tumor metastasis through an angiogenesis-dependent mechanism mediated by epha receptor and vascular endothelial growth factor in mice. Cancer Res 2006;66:10315-10324.

53 Chen J, Hicks D, Brantley-Sieders D, Cheng N, McCollum GW, Qi-Werdich X, Penn J: Inhibition of retinal neovascularization by soluble epha2 receptor. Exp Eye Res 2006;82:664-673.

54 Baldwin C, Chen ZW, Bedirian A, Yokota N, Nasr SH, Rabb H, Lemay S: Upregulation of epha2 during in vivo and in vitro renal ischemia-reperfusion injury: Role of src kinases. Am J Physiol Renal Physiol 2006;291:F960-971.

55 Zhou N, Zhao WD, Liu DX, Liang Y, Fang WG, Li B, Chen YH: Inactivation of epha2 promotes tight junction formation and impairs angiogenesis in brain endothelial cells. Microvasc Res;82:113-121.

56 Vihanto MM, Plock J, Erni D, Frey BM, Frey FJ, Huynh-Do U: Hypoxia up-regulates expression of eph receptors and ephrins in mouse skin. FASEB J 2005;19:1689-1691.

57 Gavard J, Gutkind JS: Vegf controls endothelial-cell permeability by promoting the beta-arrestin-dependent endocytosis of ve-cadherin. Nat Cell Biol 2006;8:1223-1234.

58 Wong BW, Rahmani M, Luo Z, Yanagawa B, Wong D, Luo H, McManus BM: Vascular endothelial growth factor increases human cardiac microvascular endothelial cell permeability to low-density lipoproteins. J Heart Lung Transplant 2009;28:950-957. 